\title{
Early-Onset Idiopathic Growth Hormone Deficiency within KIGS
}

\author{
Michael B. Ranke ${ }^{a}$ Anders Lindberg ${ }^{b}$ \\ on behalf of the KIGS International Board \\ aPaediatric Endocrinology Section, University Children's Hospital, Tübingen, Germany; \\ bKIGS/KIMS Outcomes Research, Pharmacia AB, Stockholm, Sweden
}

\section{Key Words}

Growth hormone - KIGS - Growth hormone deficiency • Early-diagnosed growth hormone deficiency • Late-diagnosed growth hormone deficiency · Children

\begin{abstract}
Growth hormone ( $\mathrm{GH}$ ) deficiency is normally diagnosed when the affected child is between 6 and 8 years of age and a lack of normal growth first becomes noticeable. Some patients, however, are diagnosed as being $\mathrm{GH}$ deficient at a relatively young age ( $<2$ years). These patients differ from the later-diagnosed patients in terms of their background, their characteristics of $\mathrm{GH}$ deficiency (GHD) and their response to $\mathrm{GH}$ replacement therapy. The analysis described in this article examined the similarities and differences between children in these categories identified from KIGS (Pharmacia International Growth Database). The results showed that although early-diagnosed patients had more severe GHD, they were much more responsive to $\mathrm{GH}$ therapy. Thus, it is suggested that early diagnosis and initiation of treatment in GH-deficient patients is strongly needed to achieve the maximum effects from therapy.
\end{abstract}

Copyright @ 2003 S. Karger AG, Basel

\section{Introduction}

Growth hormone $(\mathrm{GH})$ deficiency is often not diagnosed in children until a relatively late stage of childhood, when the lack of normal growth first becomes apparent. There is, however, a subset of patients in whom GH deficiency (GHD) is recognized at a much earlier age $(<2$ years) and the early diagnosis of GHD and initiation of treatment have been reported to have a positive effect on the final outcome $[1,2]$.

Two groups of children have been identified in KIGS (Pharmacia International Growth Database) - those who were diagnosed with GHD at an age of less than 2 years and those diagnosed at the typical pre-pubertal age of 6-8 years. These groups were compared in order to identify differences in the characteristics of their background and disease profile, as well as in their response to GH therapy. The use of growth prediction models to analyse these subgroups of patients was also investigated.

\section{Patient History}

In total, 1,732 children were included in the analysis; 234 were diagnosed with GHD before the age of 2 years and 1,498 were diagnosed between the ages of 6 and 8 years (average age of patients, 6.85 years) (table 1 ).

\section{KARGER \\ Fax +41613061234 \\ E-Mail karger@karger.ch \\ www.karger.com \\ (C) 2003 S. Karger AG, Basel \\ 0301-0163/03/0607-0018\$19.50/0 \\ Accessible online at: \\ www. karger.com/hre}

Prof. M.B. Ranke

Paediatric Endocrinology Section, University Children's Hospital

Hoppe-Seyler-Strasse 1, DE-72076 Tübingen (Germany)

Tel. +497071 298 3417, Fax +497071294157

E-Mail michael.ranke@med.uni-tuebingen.de 
Interestingly, although it may have been expected that the early-diagnosed group would have a lower birth weight and length, the birth weight was higher in this group and the birth length was similar between the two groups. Despite the similarities between the two groups, however, there are also some differences. Firstly, parental height differed considerably between the two groups, with patients in the later-diagnosed group having parents of much shorter stature. Whether parental height is a factor in the development of GHD, however, remains in question. The early-diagnosed patients were found to have more severe GHD, with a significantly lower maximum level of GH. In addition, these patients were more likely to suffer from multiple pituitary hormone deficiencies than the later-diagnosed group.

Complications at birth are more frequent in individuals with idiopathic GHD than in the normal population. In a Swedish study, the proportions of individuals with idiopathic GHD delivered breech or by caesarean section were 7.1 and $16.6 \%$, respectively, compared with 2.8 and $10.4 \%$ for the whole population [3]. Of the patients in the study discussed here, complications at birth were more frequent in the early-diagnosed group (table 2), with $10.7 \%$ born by breech delivery and $24.8 \%$ by caesarean section. It has been suggested that trauma at birth may be a cause of GHD, as a result of the development of cerebral lesions [4]. It is also possible, however, that the reverse is true and that complications at birth could occur because of disorders of the pituitary gland and GHD. The debate regarding which of these hypotheses is correct is still ongoing.

\section{Response to Therapy}

\section{Patient Characteristics at Diagnosis}

The effects of treatment with GH therapy between the two groups were compared over a 1-year period. At the start of treatment (table 3), patients in the earlydiagnosed group had more severe GHD and stunted height. Comparing these data with those at birth (table 1 ), it can be seen that over a period of less than 2 years, the patients from the early-diagnosed group had changed from -0.60 standard deviation score (SDS) to -3.54 SDS of normal height. This considerable reduction in growth indicates the critical role of GH during these early years of life. There is a delayed shift in GH sensitivity after birth - growth is initially less independent of $\mathrm{GH}$, explaining the relatively normal birth length and weight of the early-diagnosed patients. GHD
Table 1. Background data for the early- and late-diagnosed children with idiopathic GHD

\begin{tabular}{lcc}
\hline & $<2$ years & $6-8$ years \\
\hline Patients, $\mathrm{n}$ & 234 & 1,498 \\
Male, \% & 66 & 67 \\
Gestational age, weeks & 40 & 40 \\
Birth weight, SDS & -0.32 & $-0.75^{*}$ \\
Birth length, SDS & -0.60 & -0.51 \\
Height of mother, SDS & -0.23 & $-0.70^{* *}$ \\
Height of father, SDS & -0.05 & $-0.56^{* *}$ \\
Maximum level of GH, ng/ml & 4.00 & $6.50^{* *}$ \\
Multiple pituitary hormone deficiencies, \% & 50.4 & $13.8^{* *}$ \\
\hline$* \mathrm{p}<0.01 ; * * \mathrm{p}<0.001$. & & \\
\hline
\end{tabular}

Table 2. Birth complications in the early- and late-diagnosed GHdeficient patients

\begin{tabular}{lcc}
\hline Delivery & $\begin{array}{c}<2 \text { years } \\
(\mathrm{n}=234)\end{array}$ & $\begin{array}{l}6-8 \text { years } \\
(\mathrm{n}=1,498)\end{array}$ \\
\hline Normal, \% & 65.5 & $77.3^{*}$ \\
Breech, \% & 10.7 & $4.8^{* *}$ \\
Caesarean section, \% & 24.8 & $17.9^{* *}$ \\
Vacuum, \% & 5.9 & $2.3^{*}$ \\
Hypoglycaemia, \% & 30.4 & $2.7^{* *}$ \\
Microphallus, \% & 27.5 & $1.8^{* *}$
\end{tabular}

$* \mathrm{p}<0.01 ; * * \mathrm{p}<0.001$

Table 3. Data for the early- and late-diagnosed GH-deficient patients at start of treatment

\begin{tabular}{lcc}
\hline & $<2$ years & \multicolumn{1}{c}{$6-8$ years } \\
\hline Patients, $\mathrm{n}$ & 234 & 1,498 \\
Age, years & 1.42 & $6.85^{* *}$ \\
Bone age, years & 0.75 & $4.50^{* *}$ \\
Height (Tanner), SDS & -3.54 & $-2.44^{* *}$ \\
Height (mid-parental height), SDS & -3.28 & $-1.69^{* *}$ \\
Body mass index, SDS & -0.83 & $-0.30^{* *}$ \\
Dose of GH, mg/kg/week & 0.26 & $0.21^{* *}$ \\
\hline
\end{tabular}

$* \mathrm{p}<0.01 ; * * \mathrm{p}<0.001$ 
Table 4. Data for the early- and late-diagnosed GH-deficient patients after 1 year of treatment

\begin{tabular}{|c|c|c|}
\hline & $<2$ years & $6-8$ years \\
\hline Patients & 167 & 1,145 \\
\hline Age, years & 2.42 & $7.97 * *$ \\
\hline Bone age, years & 1.80 & $6.00^{* *}$ \\
\hline Height (Tanner), SDS & -1.61 & $-1.83^{*}$ \\
\hline Height (mid-parental height), SDS & -1.75 & $-1.06^{* *}$ \\
\hline Height velocity, $\mathrm{cm} /$ year & 14.30 & $8.51^{* *}$ \\
\hline Change in height from start of treatment, SDS & 1.93 & $0.61^{* *}$ \\
\hline
\end{tabular}

$* \mathrm{p}<0.01 ; * * \mathrm{p}<0.001$

becomes increasingly evident during the first few years of life, when growth becomes GH dependent and the sensitivity to GH increases.

Within the early-diagnosed group, two cohorts appear to exist, the first of which consists of patients of relatively normal height and the other consisting of patients who are considerably below normal height. Patients with relatively normal height may have other symptoms of GHD including hypoglycaemia, micropenis and icterus prolongatus. The children in the early-diagnosed group as a whole were noted to have a much higher frequency of hypoglycaemia at birth (table 2).

\section{Patient Characteristics after 1 Year of Treatment}

After 1 year of GH replacement therapy, the average height in the early-diagnosed group had increased to -1.61 SDS of expected height (table 4). This increase in height of 1.93 SDS was significantly greater than the increase in the later-diagnosed group (0.61 SDS; $p<$ $0.001)$. Consequently, the calculated height velocity was also significantly greater in the early-diagnosed group than in the later-diagnosed group. In addition, other studies have suggested a favourable outcome of GH treatment in very young children $[5,6]$ and the results from KIGS presented here confirm that there is a greater response to $\mathrm{GH}$ administration in young children.

\section{Growth Prediction Models}

Growth prediction models contain variables that influence the response to GH therapy in a defined group of patients over a fixed period of time. These models have previously been developed using data from KIGS [7, 8]. The development of a prediction model ideally requires:

- a large number of participants

- a well-defined population with a specific disorder

- heterogeneous clinical characteristics

- easily determined, standardized and reproducible variables.

In addition, the model should have a high predictive power and accuracy, i.e. explained variability $\left(\mathrm{r}^{2}\right)$ should be high and error of prediction should be low. The model should also possess practicality, robustness and validity as it will be tested independently on patients from this population. From the results of the model, the studentized residual can be calculated; this is an index of responsiveness used to determine the accuracy of the prediction. The predicted growth rate is compared with the actual growth rate for each patient. A higher studentized residual equates to a greater response.

Data obtained from 593 patients in the later-diagnosed group were evaluated using a growth prediction model. From this model, $\mathrm{r}^{2}$ was found to be 0.61 and the error of prediction was $1.5 \mathrm{~cm} /$ year. The most important predictors of response to GH therapy were found to be (in order of importance):

- the degree of GHD (the more severe the condition, the better the response)

- the age of the patient (the younger the age, the better the response)

- the distance to target height (the greater the distance, the better the response).

Other predictors included weight, dose of GH therapy and birth weight.

In the later-diagnosed group, the studentized residual was calculated to be -0.21 . As yet, the prediction model has only been validated for the later-diagnosed group and has not been developed for children less than 2 years of age. Nevertheless, the model was applied to the early-diagnosed group and assumed to be still valid. When the studentized residual was calculated for the early-diagnosed group, the value of 1.24 was significantly different. This is indicative of a greater response to GH therapy and confirms that the response to $\mathrm{GH}$ is better in younger patients. This occurs because there is a heightened sensitivity to $\mathrm{GH}$ at this young age, when growth becomes $\mathrm{GH}$ dependent. By adulthood, growth is complete and the dose of $\mathrm{GH}$ required to normalize body composition is usually much lower. It is clear that treatment at an early age is beneficial and allows patients to achieve their target height by the time they reach puberty $-\mathrm{a}$ factor that has been found to be a strong indicator of final adult height [5]. 


\section{Conclusion}

Patients with very-early-onset GHD ( $<2$ years) possess a number of characteristics that are different from those seen in patients who develop GHD at a later stage of childhood. While the two groups show similarities at birth, individuals who have an early onset of GHD typically present with more severe symptoms and have a higher incidence of multiple pituitary hormone deficiencies.
They are also more likely to have suffered complications at birth, and yet have parents of relatively normal height.

Overall, GH has good efficacy in very young patients. The responsiveness of the early-diagnosed group to $\mathrm{GH}$ therapy was much greater than in the older patients, probably due to the heightened sensitivity of the younger patients to $\mathrm{GH}$. These results highlight the need for rapid diagnosis of GHD and treatment in all patients, in order to gain optimum results with $\mathrm{GH}$ therapy.

\section{References}

1 Job JC: Early diagnosis and early treatment of growth hormone deficiency. Horm Res 1989; 31:149-152.

2 Vanderschueren-Lodeweyckx M, Van den Broeck J, Wolter R, Malvaux P: Early initiation of growth hormone treatment: influence on final height. Acta Paediatr Scand Suppl 1987; 337:4-11.

3 Albertsson-Wikland K: Birth data for children with growth hormone deficiency: a preliminary analysis of a national registry. KIGS Biannual Report 1990;4:19-27.
4 Bierich JR: Aetiology and pathogenesis of growth hormone deficiency. Baillieres Clin Endocrinol Metab 1992;6:491-511.

5 De Luca F, Maghnie M, Arrigo T, Lombardo F, Messina MF, Bernasconi S: Final height outcome of growth hormone-deficient patients treated since less than five years of age. Acta Paediatr 1996;85:1167-1171.

6 Rappaport R, Mugnier E, Limoni C, Crosnier H, Czernichow P, Leger J, Limal JM, Rochiccioli P, Soskin S: A 5-year prospective study of growth hormone $(\mathrm{GH})$-deficient children treated with $\mathrm{GH}$ before the age of 3 years. French Serono Study Group. J Clin Endocrinol Metab 1997;82:452-456.
7 Ranke MB, Price DA, Albertsson-Wikland K, Maes M, Lindberg A: Factors determining pubertal growth and final height in growth hormone treatment of idiopathic growth hormone deficiency. Analysis of 195 patients of the Kabi Pharmacia International Growth Study. Horm Res 1997;48:62-71.

8 Ranke MB, Lindberg A, Guilbaud O: Prediction of growth response to treatment with growth hormone; in Ranke MB, Gunnarsson R (eds): Progress in Growth Hormone Therapy 5 Years of KIGS. Mannheim, Germany, J \& J Verlag, 1994, pp 97-111. 